\title{
The Relationship between Theory, Scientific Explanation and Statistics in the Social Sciences
}

\author{
Laura Ibarra García \\ Additional information is available at the end of the chapter \\ http://dx.doi.org/10.5772/intechopen.75117
}

\begin{abstract}
This chapter presents the criteria that sociological explanations and theories must cover and their role in empirical research based on quantitative methods. These criteria are: (1) must regain the phenomenon's intrinsic causality; (2) must reconstruct the conditions in which a social phenomenon surges and develops, although a historical methodology is insufficient in many cases; (3) must develop a second-order observation. Empirical sociological research that resorts to the quantitative method is among first-order observations. The second-order research are those that makes the first-order observations their subject of observation, which is why sociology, unlike other sciences, is a discipline that has itself as object of study (the sociology of sociology); and (4) must separate the intentions of the actors' actions from their effects. The first-order observation based solely on establishing statistical relationships, such as those performed by sociobiology, can offer the appearance of high scientific validity. In its last part, this chapter offers an example of the need to complete or reject data with second-order theoretical observations.
\end{abstract}

Keywords: theory, explanation, statistics, modern thinking, first-and second-order observation

\section{Introduction}

This chapter answers the following question: what relationship is there between the datagathering and statistically oriented empirical research and the theoretical formulation and explanations of the social sciences? Even though it might seem obsolete after the discussions promoted by the rise of positivism, this question has obtained renewed relevance, due, 
among other reasons, to the predominance of the comparative-descriptive method in sociological and psychological research and that it has become one of the main analysis methodologies for society. Away from other debates, the comparative-descriptive analysis's only justification is its empirical reference; its goal doesn't offer anything beyond a picture of the similarities and differences observed in national societies. For example, there are investigations about the differences in moral values or unemployment, birth, marriage, divorce, mortality rates, and so on. This stems from the conviction that the comparison between social groups or between regions within a nation facilitates getting to know a society. Indeed, its results make it clear that there are differences within societies, for example, between north and south, east and west, and so on. However, these differences between one region and another, between the north and south of Italy, for example, tell very little about what makes the Italian society a society. This type of research appeals to empirical researchers or sociologists, although it barely helps to explain the emergence of society as a rising phenomenon. Society does not result from it. Many of its parts are classified and assessed, but their sum does not make a society [1].

Another reason why it is important to ask the question about the relationship between the statistical data elaboration method and theory is the current conditions in social science research. Subjected to the logic of project financing, many observers of society are forced to present "useful" results, inspired by logical positivism. At the end of their work, they invariably maintain that their conclusions have been rigorously tested, that they are based on first-hand experiences, and that they have resulted from logical analysis. The result has been a colossal amount of empirical knowledge, which is hardly the object of a second-order observation, with explanatory aims, or rebuttals that lead to social theories.

In terms of Piaget's theory, it could be said that a formal-operational thinking exercise, which considers the thought and not only reality itself, is needed [2]. Data alone say nothing. To understand it, a reasoning is necessary that thoughtfully relates it to ideas that give it a meaning. Concisely, it can be said that there is too much sociological research and a growing theoretical deficit. One of the reasons that have led to this is easily identified: in terms of projects financing, the institutional preference to support quantitative research that provides immediate political usefulness instead of the thoughtful sociological observation.

Another reason why we are inclined to consider the relationship between empirical research and the scientific and theoretical explanation is the recent emergence of a global society and regional societies of considerable dimensions, for example, the European society, which represents a challenge for quantification and theorization [3]. So far, the comparative-descriptive method and its statistical resources in sociological research had application within the limits of national borders [4]. When we look at the reports provided by the institutes devoted to statistical information, as well as the publications resulting from empirical research in social sciences, it is possible to argue we are before a "nationalist" methodology [4]. The nation state constitutes the basic unit for the calculation of every social research [5]. However, comparative-descriptive research has broadened its application area. Studies, like those performed by the OECD in its member states or those done by the European Union through academic 
agencies or institutions, gather valuable information about nation states' populations and analyze their similarities and differences. However, as indicated before, these comparisons help to understand that there are significant differences between countries, for example, they help us to understand that the economies of Mexico and Germany are very different, but their contribution to understand the world order's reorganization or the globalization processes is not very significant. The challenge for quantification does not derive from the comparison between countries with similar social structures but between large regions. Undoubtedly, the European national societies can be compared to each other since they are units with multiple similar internal factors in a homogeneous social space and can be seen as elements of an institutionally defined space that encompasses them. However, what can Europe, for example, be compared with? Obviously, only with something comparable; with the United States, or China, or Latin America, probably [1]. However, due to the large dimensions of these units, their complex internal structures of subunits, which interact in a very particular manner, and their lack of a common space, it is difficult to establish comparison points. In addition, the way to compare regions in a way that contributes to understand the formation process of a global society is an open question.

To identify the contribution of quantitative strategies to the formulation of theory, we must pay attention to the conditions social sciences thought theories must fulfill. For this, we must first explain what is meant by "modern thinking." From this follows a guide for the construction of any social theory. Once the logical cognitive scheme every scientific explanation should be based upon is presented, the chapter describes the requirements that should be covered by any explanatory or theoretical reflection. First, it points out the need to resort to the conditions in which a phenomenon emerges. Any object or event results from a formation process that must be causally observed and reconstructed to achieve an explanation. This is also true in natural sciences, indispensable to understand diseases or the characteristics of a territory, for example.

Subsequently, the chapter addresses the distinction between first- and second-order observations, which allows us to distinguish between the empirical research activity and a reflection that relates the results of this activity to the wealth of conceptualizations and theories, which constitute a solid knowledge and have achieved the understanding of other phenomena, or, in any case, constructs it.

Separating the intentions of the members from their effects has resulted essential for the study of societies. Society is no longer seen as the result of a collective idea inspired on the achievement of the common good. Therefore, in the next point, this distinction is addressed, which allows for the entry of categories such as power, competence, or conflict, to explain the dynamics of social order and places morality as a relevant means only in a community where the neighborly, kinship, or face-to-face relationship ties prevail.

Then, we identify three requirements that may be considered the starting point for any explanation and theorization. In each of them, the role played by quantification is indicated. Given the results of statistical instruments that are often linked to assumptions that escape empirical verification, I present a sociobiology study at the end as example, which is supported by a 
rigorous statistical exercise but whose premises and conclusions lack an analytical foundation. Absent this, most thesis, no matter how crazy, can find a statistical basis to give it some credibility.

Surely, at this point, specialists in empirical research await an explanation of the observations' methodology followed in this chapter, but methodological strategy is a procedure proper of the first-order observations, as we will see hereunder.

\section{Requirements for scientific explanations}

To answer the question about the relationship between the statistics producing research and the scientific explanation, it is necessary to first analyze how explanations are formulated in social sciences. The emergence of natural and social sciences is closely linked to a fundamental change in the historical development of thought that occurred at the beginning of the modern era. This change is particularly characterized by a break in the logic applied to understand and explain the phenomena of the world, or, in a given case, the world itself. Therefore, we must clarify what "explaining" means in the modern sense. From this surges every approach for society's theory construction as second-order observation. This radical transformation in the scheme or logic of thought, which may well be understood as a cognitive paradigm, should be understood as the basic condition for the development of any explanation or theory that claims scientific validity.

\subsection{The desistance of absolutes as explanation}

"The ancients" thought every phenomenon through until they recognized "one clear terminus" [6]. Nowadays, scientists agree that any hypothesis must desist from claiming an absolute origin that provides the ultimate argument. This is the result of the world's process of secularization that accompanied the three modernity revolutions: the revolutions in the natural sciences, in politics, and in economics.

From the epistemological point of view, this means that it is not possible to understand what exists as the product of an absolute origin and that all questions regarding its cause are answered by resorting to a single ultimate origin. Günter Dux explains this way of proceeding: "The absolute in premodern thinking, where spirit predominates, was absolute because it contained what was to come out of it as substance. The way of explaining consisted of attributing the explanation to the absolute to make it rise from there as an emanation." [7]. The explanatory potential of resorting to the absolute resided in the impossibility to question it. It was impossible to explain something within this logic, since the absolute origin subtracted itself from the question about its own cause. In this regard, Dux points out: "In a world that turned radically secular, in which... nothing that subtracts itself from a set of conditions can be found, the constructively achieved worlds - and their logics - must be explained through the conditions that made it be" [7]. Then, it's not that a certain explanation lost its convincing power along the history of thought, but the substitution of an explaining logic for another, of 
a paradigm for another. According to the old logic, explaining meant to part from the concrete object or phenomenon - natural or social - and to assign it an ultimate origin to claim it as its cause. This way of proceeding forced us to think of the cause as an origin analogous to what would emerge from it. Cause and effect were (partially) identical.

The attempt to find explanations through this process lost strength for the same question about the origin that could not be answered by resorting to an absolute origin anymore, not without falling into an endless return.

Accordingly, every form of explanation where the explainer is present in the initial explanation from which it emerges is unsatisfactory, for example, in the explanation of a social phenomenon where the said phenomenon is already embedded in the actors' wills, or in the explanation of specific social phenomena that are already in the own qualities of that society [4].

Modern thinking imposes then a first requirement for sociological research: it is not feasible to opt for a research strategy where the concept is defined beforehand to apply it then to the phenomenon being researched; we would rather have to work the other way, we must perform an observation and then specify how it developed.

\subsubsection{The survival of the old explanatory scheme}

Nevertheless, in many modern sociological and psychological theoretical approaches survive remnants of the absolutist and substantialist logic, which are especially visible in sociology's classical theories and authors because during the historical transition from one logic to another-and despite their attempt to abandon the old explanatory scheme-they retain the idea of an absolute as explanation, but under a different tag. In Durkheim's sociology of religion, for example, "society" is attributed to all forms of religious thought, but this concept in his theory does not provide any information about the creation process of mental constructions. Society is the only origin of the social. With regard to religious phenomena, Durkheim reaffirms the formula that inspired his sociological theory and is based on the identity logic that resort to the Absolute. In it, "society" appears as the origin and cause of all phenomena that require explanation.

The general result of the book (The elementary forms of religious life) is that religion is a prominently social issue, religious ideas are collective ideas that express collective realities: rites are behaviors that can only arise within groups and must be useful to maintain or restore certain psychic states of these groups [8]. In a different place: "just like the concept of religious power and divinity, the concept of soul is not devoid of reality...since society - the only source of everything sacred - is not content with moving us from outside temporarily; it is permanently installed in us." [8].

As shown, Durkheim's concept of society is an ontological construction placed in an allexplaining position by theory, and society precedes everything which sabotages any other possible explanation. The best proof that we are dealing with a secularized form of the metaphysical structure of thought is provided by Durkheim himself, when he declares that it will be necessary to choose between god and society as explanation [9]. 
A similar structure is behind several philosophical approaches. For example, in moral philosophy, any attempt to discover the origin of morality already involves morality itself. In philosophy, during the fundamentation process, what is intended to be justified is already given. In its explanatory reflection, what is to be explained is already in the explanation: language is in the origin of language, communication is in the origin of communication, and morality, of course, is derived from morality. In the transcendental theory of knowledge, morality as a part of reason comes, of course, from reason, but not as a slowly forming construct along the human societies natural history-having as a condition the brain in which the reason is not contained beforehand-but in its substantial form, which holds what will emerge from it [10].

Likewise, a fall in premodern absolutist logic also occurs in current theoretical approaches, which attribute certain characteristics to the concept of society, and then the phenomena in this society are seen as consequences of those characteristics. This circularity is found, for example, when it is affirmed that the risk society contains several risks, the society of options offers many options, or that in the society of experience many things can be experienced. All the previous statements are late absolutist historical manifestations, in which finding an explanation means to derive effects from a cause established a priori, and in which they are already contained. This same logic underlies the systems theory when it says that the explanation of the differences in society requires as starting point the unit of the system of society that creates these differences. With the development of thinking in the modern era, this construction of the concept of society results obsolete [4].

Hence, it is only possible to scientifically accept a concept of society when it allows to explain what is to be understood by resorting to empirically verifiable actions in society and asking about the existing conceptions of society in praxis. For example, when society is conceptualized as reciprocal forms [11] or as "a network of connections of practical forms, in which men lead their lives" [12].

The concept of society must be pointed toward the relationships between elements and must neither admit absolutist nor substantial connotations. Vobruba even recommends desisting from a pre-formulated definition of society. He points out that this does not mean the end of a theory of society; rather, it opens the possibility to articulate a theory with empirical content. A theory that can clarify the existing phenomena in practice and can question its causes and its effects [4].

Evidently, in this sense, empirical research, including that which uses quantification and variable relations, can be a very valuable instrument for the process of articulation of a concept of society. If sociology must deal with social and political events subject to a network of actions and social relationships in which these events occur and produce effects, the analysis that empirically verifies them, classifies them, and evaluates them represents a first and valuable step for a latter theoretical exercise that must retake them and explain them. This way of proceeding ensures that the explanation will not be included in the explainer, instead, the explanation will resort to the elaboration of a complex relationship between causes and effects based on data that portrays reality, that is, that ensure an empirical content. 


\subsection{What does explaining mean?}

If scientific explanations must desist from resorting to the absolute as argument, what must they appeal to then?

Günter Dux very precisely points out what the change in the logic of explanation consists of: the absolute is discarded to recover the real causes of the phenomenon itself, in other words, a causality that thought imposes on phenomena is abandoned, to reflexively reconstruct the real causes inherent to the observed process, that is, the objective relations between things [10]. Therefore, the historical decline of absolutist logic as explanation for the phenomena was accompanied by the emergence of the diversity of science. At the beginning of the modern era, it was no longer possible to resort to an ultimate cause, but each phenomenon showed specific determinants that gave rise to the different sciences. A lengthy list of systems replaces the limited relationships of the previous logic. According to Piaget:

"There are logical operations such as those resulting from a class system (meeting of individuals) or relations, arithmetic operations (addition, multiplication, etc., as well as their investments), geometric operations (intersection, deviations, etc.), temporary operations (ordering sequences of events and insertion of intervals), mechanical, physical operations, etc." [13].

In social sciences, the study of the conditions in which cultural forms of life arise made it visible that a methodological strategy that assumed the incorporation of history as explanation was required. To understand social phenomena, it was inescapable to resort to their formation process, their development. Although the theories of sociology's classic theorists, like Durkheim or Marx, have lost their explanatory power for distinct reasons, they have at least the merit of introducing history's explanatory role. The importance of The Capital for the development of knowledge consists of following: the formation of economic development from its genesis, first in the commercial capital and then in the industrial capital of the eighteenth and nineteenth centuries.

In the case of psychology, regardless of the current value attributed to psychoanalysis, identifying mental pathologies as the result of traumatic experiences during the history of the individual was the fundamental contribution of Freudian theory. Albeit, a single experience and experience type-sexuality-were given too much importance, psychic disturbances found their explanation in the subject's own past. Nowadays, everyone accepts the close relationship, discovered by the Freudianism, between an individual's affectivity and his past, especially his childhood [13]. Everything looks different after a revolution.

However, it must be emphasized that scientific work consists of apprehending the intrinsic causality in the dynamics of the process. Every sociocultural form of life can only be explained if one resorts to the conditions in which it started and under which it has continued developing. This is what Marx means when he says that there is only one science: history [14].

As we have seen, explaining is a concept that assumes a specific meaning in social theories: it is about reconstructing the conditions in which the sociocultural forms of organization emerged and then evolved. 
A scientific explanation can set spatial and temporal limits to the observation period of the conditions in which the social phenomenon of interest arises, while a theory must contemplate the core aspect of all its development. It must be capable of generalizing in a way that its application covers broader periods of time or a wider range of phenomena.

In a social science theory, the starting point is the set of constellations formed by systematically organized conditions that influence each other and that only in their joint action give rise to the result. In this sense, the methodological logic that is followed is a relational and systemic logic. However, it is also a procedural logic. By this, we mean that the result, the thought, language, or morality organization forms are not found within the constellation of conditions that constitute the starting point. The result is formed in the process. The difference with the methodology followed by philosophy is evident: in philosophy's logic of derivations, there never is a new phenomenon. Within the procedural logic, there is room for a new phenomenon to arise: life can surge from lifeless matter, from life devoid of spirituality, cognition, language, or morality rise.

However, the reconstruction of the conditions in which the sociocultural forms of life were formed represents only the first step. If we intend to objectively and scientifically analyze the sociocultural forms of life, including current ones, it is necessary to explain why the sociocultural forms of life developed and grew in a specific way. Of course, this approach involves the task of reflecting on the development of history in its entirety. However, a sociological theory is not about advancing the knowledge of the succession of events in their outward appearance, but to follow the footsteps of something like a development logic that sustains the process. Marx already tried this regarding production systems when he found out that the development of the productive forces in human history follows a line that started with hunting and gathering, continues with the agricultural forms of production and all the way till reaching industrial production. And, who would dare today to deny that, in this sense, social evolution is moving in this direction and hence follows a logic? In the same way, Piaget endeavored to demonstrate that the ontogenetic cognitive development parts from a sensory-motor intelligence go through the preoperational stage until reaching the operational and formal-operational stages. And although in the 1980s, a discussion arose regarding the universality of the sequence of stages, epistemologists do not hesitate to admit that cognition is subject to development and that it registers a logic, as Piaget formulated it.

The postmodernist idea that history follows the irrationality tenet undermines the knowledge that countless empirical studies have achieved, and we can consider reliable information. At this point, the postmodern stand is only based on the reluctance to place oneself in the field of knowledge that empirical studies have made available. History is not simply the sequence of innumerable events in which each of them differs from the previous state, the sequence of life forms with which man becomes accessible and reality follows a logic of development. This is precisely what a theory seeks to prove. History, as a man-determined history, in which he interprets himself, is susceptible to explanation. In a rigorous analysis of history, it is not possible to argue that the development has lacked logic, neither in its beginning, nor in its direction. If history is understood as a series of life forms in which man becomes accessible to the 
world and interprets himself in it, then it becomes evident that development possesses a logic. However, the historical method is not enough for everything [13].

Although one might think that the social sciences should resort to history, this does not necessarily mean a remote past that goes to the very process of formation of the constitution of the anthropological species, the conditions in which a phenomenon arises and develops to include conditions in the present or recent history, which require empirical verification, especially in their causality and effectiveness. Quantitative studies provide valuable information that can be considered the solid foundation for the explanations and theory formulation. To this condition is added a third that distinguishes sociology from other disciplines of the social sciences.

\subsection{Society under two observation perspectives}

To answer the question: what should we consider a scientific approach in a science of society? We first must bear in mind that there are two orders of observation and interpretation [15]. An observation of the first order is the people's perspective, who observe and interpret social relations and, according to this, act. In the second-order perspective, people's actions, along with their observations and interpretations, are sociologically observed.

The main difference between the first-order observations level and the second-order observations level lies in the people, which act in relation with a reality on the foundation of their first-order observations, while second-order sociological observations are not linked to the action. Any sociological definition of society must include as reference the actions of the members of society and the knowledge of their actions in which "society" can be identified. Since society is built even without sociology's participation, sociological observation must adhere to the way in which people observe and interpret social relationships and act in society accordingly. As sociology observes and interprets the observations, interpretations, and actions of the people, it assumes the reality with which people act and thus escape the danger of constructing arbitrary conceptualizations, since people's interpretations cannot be of any kind if you do not want actions to cause any damage.

Andreas Balog points out that the solid foundation on which the formulation of a concept is based, what provides certainty over the identity of the social phenomena and sets limitations to sociological categorization, is common knowledge, which constitutes the basis for the orientation of the actors in their daily world and is manifested in their actions and in the language of daily life [16]. In this sense, sociology is always a second-order observation.

Thus, since sociology is a second-order observation, its subject of study is society in the sense that there is a group that understands itself as society. It is totally irrelevant if the sociologist thinks there are no reasons to consider that Paraguay and Uruguay are two different societies, what matters is that for the people living in Paraguay and Uruguay - that is, in the firstorder observation - there are enough differences to consider them as two different societies. In the second-order perspective, the concept of society is applied to recover what in society (as empirical group) is perceived and interpreted as society. The concept of society in the second order of observation is that which exists and acts in society. 
Given that everything in society can be observed in the second-order sociology, even sociology itself, the observes can become themselves observable, or first-order observers. And, since everything observed from the second-order perspective turns into first-order observation, empirical sociological research becomes first-order observation and sociologists themselves become "the people" [4]. When this occurs, it is observed how sociologists observe, interpret, and act in the sociological practice. According to Vobruba, sociology can have itself as object of study, since it can become its own object of observation (id.).

In the sociological perspective of first-order observations with the purpose of conducting research, the concept of society can only be required to cover the field of study. Hence, the concepts of society cannot be considered as true or false, but simply as practical or impractical. Every sociologist, or first-order observer, can formulate a concept of society and deduce the consequences that result from it. Sociology's scientific means do not allow to establish "the right concept of society." Therefore, each author can formulate their own concept, and it can also be expected for other observers to present their own different concepts, which can be documented empirically with the number of concepts of society available [4].

This differentiates sociology from other disciplines. There cannot be a medicine of medicine, nor a legal science of social science, nor an economics of economics. However, there is a sociology of medicine, a sociology of law, a sociology of economics, and, also, a sociology of sociology in the sense that a sociological analysis of the cognitive requirements sociology must present.

Statistics is a first-order observation. However, this is a better knowledge than which comes straight from the senses and which has a subjective character. In this context, better means a more direct picture of reality. Hard data are an attempt to understand objective reality in a more precise and correct way. However, data alone do not say anything. Second-order conceptual research is necessary to place it in a context that gives it meaning.

\subsection{Separating intentions and consequences in social integration}

In the past, the concept of society used to designate social groups that were intentionally established and were aimed for specific objectives. At the beginning of the modern era, society was understood as an intentional institution of equals (bourgeois) for economic purposes. Because of this, the concept was used in a more plural often. In the seventeenth and eighteenth centuries, Hobbes, Locke, and Rousseau thought of society as the product of a constitutive act at some point in history, the result of their intention to ensure peace, protect their property, or a willingness to ensure equality and the freedom. Society was understood as the product of a social pact that ensured its future integration. Later, the concept of society was transferred to problems of social order, which maintained the intentional structure of the understanding of society. It was believed that, due to the importance of politics as a guiding system for society, it was possible to translate the intentions into any desired political model, society was thought of as a malleable political entity.

Durkheim strove to overcome the vision of a society built by a social agreement or to discard the idea of an "invisible hand" that regulated social relations. Because of the division 
of labor, men in modern society find themselves increasingly in dependency relationships, which moderates their selfishness and converts them into moral beings. "In one word: since the division of labor becomes the main source of social solidarity, it simultaneously becomes the basis of the moral order" [17]. Society's integration is the result then of a single principle: the moral order. However, modern society, unlike a community in which relationships occur face to face, is not based on morality. The term "community" is applied to premodern relationships, in which ties of kinship and friendship play a key role in social integration, but in society this is not the case. In society, a shared morality, outside of a minimum, that allows interaction, is not a condition for its constitution. From the epistemological perspective, Durkheim's thinking is halfway between the break between absolutist thinking and modern thought, between a substantialist conception of society and a conception that understands it as a rising process.

In the second third of the twentieth century, other contributions with important repercussions in the way of understanding society emerged. Among them, a new observation approach for social relationships linked to the growing inclusiveness of the concept of society was introduced. In this approach, the effects on society are seen and systematized as separate from the intentions; the individual intents can have collective consequences that distinguish themselves qualitatively from these intents. That was the beginning of the end of the idea that society is composed of individual efforts or intentions that seek social unity. The creation of a level of observation in which it is possible to separate the intentions from the effects is the requirement to deprive the social from the moralization and cognitivization. Society thus becomes an object of observation and the materialization of the effects that result from social relations.

As soon as the actions' intentions and effects are disengaged, that is, as soon as it is possible to think of society as a result of unintended effects, "the good purposes" lose their significance. With this, categories such as inequalities, power struggle, conflict, or antagonisms regain relevance in the conceptualizations of society, and solidarity and morality are reduced to a motivation for action among many others. In modern sociological theories, social phenomena can be attributed to actions, but not to the intentions that guide them.

Due to the introduction of the difference between intentions and effects and the disassociation of the concept of society from the intentions, a semantic space emerges to separate the concepts of society (unintended) and community (intended). However, there still are sociological approaches that try to explain society and all the events that happen in it by the hand of its actors' intentions, and because of this they acquire a futuristic character that starts from the good intentions of the social actors.

\section{The "short circuit" between empirical results and second-degree observation: The case of sociobiology}

Empirical research has gathered a considerable amount of valuable descriptions with its statistical-descriptive method. The main problem of these investigations is that they are 
often linked to conclusions, which are based on assumptions that are subtracted from empirical verification. This is the case of sociobiology when, before formulating the assumptions that will be verified, parts from the idea that social capabilities are contained in the genome, for example: studies that conclude a relationship between "racial ancestry" and social phenomena subject to other forms of determination. The following is stated in one of them [18], for example:

We find that European ancestry is consistently and usually strongly positively correlated with cognitive ability and socioeconomic outcomes (mean $r$ for cognitive ability $=.708$; for socioeconomic wellbeing =.643). And even further:

12 zero order correlational analyses found a substantial positive relationship between European ancestry and both cognitive ability and general socioeconomic well-being...

While the association between racial ancestry and outcomes is consistent with a genetic hypothesis, to obtain decisive evidence in support of such a position, one would need to identify specific alleles that vary between ancestral groups which are directly [19] or plausibly indirectly [20] associated with cognitive and/or socioeconomic outcomes on the individual level...[21]. ${ }^{1}$

In the conception of the individual that this study parts from, remnants of absolutist thought are still present: the sociocultural forms of life are presented as if they could be explained from a genetic a priori. In a second-degree observation, one may ask: What does this mean? How important is, for the behavior of an individual, what past generations, in the natural history of the species, have contributed as genetic material? How exactly does this material lead to certain behaviors?

This study shares the false supposition that genetics determines the cognitive level with the rest of the sociobiological investigations. The great wealth of psychogenetic and educational studies, initiated by Jean Piaget, has shown that the determinants of any individual's behavior do not reside in the genes but in learning, the actions of a subject are the result of its life experiences. The theoretical attempts to re-naturalize mental capacity have failed. To effectively evaluate the influence of the genetic background in cognitive abilities - which the study intends to show - first we need to remember the role played by the genes and the development of learning in the natural evolutionary history of the species. This way, it must be clear what biological equipment can and cannot do. Let's take a better look at this.

\subsection{Theoretical excursus}

Undoubtedly, the key to understand the cultural forms of life, including cognition, morality, love, and so on, should be sought in the natural history of the species first. The development of what characterizes the anthropological species was linked to the natural evolutionary history. Therefore, sciences try to reconstruct the development of these forms in the long transition process from animal to man. Some of the key questions sciences seek to answer are: What

\footnotetext{
${ }^{1} \mathrm{~A}$ more detailed analysis of this investigation as well as the reply of its authors can be found in [22].
} 
were the conditions that made it possible for the anthropological species to develop the capacity to learn? How was the human being formation process as such possible?

The key process to understand the evolutionary development of the anthropological species is the ontogenesis. For millions of years, our species development was characterized by two parallel processes: the dissolution of instinctive and inflexible genetically determined forms of behavior and enormous learning in the first phases of ontogenesis. Through its relationship with the person responsible for its care, the member of the species in initial stages was able to acquire experiences that allowed it to increase its actions competence and arrange reality into a comprehensible world, which led to a gradual radical change of the genetic material, so instinctive structures lost their strength as determinants of the actions. In the transition from animal to man, the lengthening of the primary relationship in ontogenetic development played a fundamental role. Everything seems to indicate the lengthening of the close motherson relationship during the first years of life, and the huge amount of learning that takes place here made the instinctive mechanisms ineffective, in a process that lasted thousands of years. In the determination of human actions, the genetic basis plays a limited role, it is only present in fields closely linked to survival, such as feeding, sexuality, and defense. The evolutionary consequence of this process is the extreme inability of the anthropological species to survive by itself at birth.

The evolution of the Homo sapiens would not have been possible if functional mechanisms for the construction behavior pattern linked to learning had not developed along with the dissolution of instinct. Brain development was key for this. Even though we do not know much about the brain's evolutionary development and the formation of differentiated neuronal zones, these made the acculturation process of men possible, and, with it, the formation of cognitive and normative structures. There is no doubt that without the brain's constructive capacity, these structures wouldn't have formed. However, it must be clear that these are only brain capacities and not cognitive competences, the latter must be acquired in a constructive way by every member of the species in their experiences in the outside world.

Since the anthropological constitution hardly has any survival instincts, the member of the species in initial stages is forced to develop mechanisms that allow it to lead an independent life. In its interaction with the adult, the new member of the species coordinates its motor skills, achieves greater competence in its actions, and develops structures that it uses to organize the world. The requirement for this to happen is precisely the social relationship with the adult in charge of its care, usually the mother. The newborn finds in her not only a figure that keeps his body alive but also a representative of the outside world from whom he learns a huge amount of behaviors and knowledge. The mother-child dyad is the stage during early ontogenesis in which the decisive learning process of survival takes place. Here begins every way of understanding reality, all the knowledge about our surrounding environment, every thought. For this reason, mother-child interaction and the mental capacities acquired in it are of paramount importance in the construction of cultural forms of life, especially cognition. 
If we consider the null cultural situation of the newborn and the interactions established in the first stage of the biography, there can be no doubt that the conditions at the beginning of the formative process at any age and in any society are the same. In every age and in all societies, for 40,000 years, the member of the species in the early stage, with nothing but a few instincts to ensure its survival, is forced to develop mechanisms that allow it to lead an independent life. It is exactly this situation which repeats everywhere what creates equality in the early cognitive structures. The same conditions in which the process takes place determine the same results. Therefore, there is no known society, present, or past, in which its members hadn't started to coordinate their motor skills or build the schemes of object/subject, space, time, and causality in the early stage. The same thing that happened to the phylogenetic development continues to occur at the beginning of every biography. At this level of knowledge, ethnic and cultural differences play no role.

As Piaget pointed out, almost every competence has a biological basis from which they part, but human competences are constructive processes, neither human conscience nor subjectivity is determined by nature, which only offers the opportunity to develop them. The newborn doesn't count with a world in order; for him, there is no space nor time, objects lack shape and permanence, and there are no causal relationships between them. Nor does he have the capacity to organize his toward an end and doesn't even perceive himself as being independent of the outside world. He will have to learn all of this through a long constructive process.

\subsection{Reconsideration of ethnic determination in cognition}

After briefly reviewing the natural history development of the anthropological species, we turn our attention to sociobiological studies.

It should be clear by now that human beings do not count with a competence for action nor a structure of the self provided beforehand by nature. He doesn't bring with him the principles of social organization, nor does it have enough knowledge of the outer world he is born into. Unlike other species, he doesn't possess an array of the natural elements that, fixed in the genetic code, reduce them to the elements relevant for action, as it happens with instinct.

If we bear in mind that at birth every member of the species is in this null cultural situation and undertakes a constructive process of the world, and that all of this happens in every society and in every age, one must ask, under the precepts of sociobiology: what is the point of trying to statistically demonstrate that belonging to a race, or genetic constitution, has any relationship with cognitive abilities?

If European, indigenous, or African children are born with a biological equipment that does not ensure their survival in any way, and all of them have the same task of undertaking the lengthy process of constructing their world and survival competences of action before them, how is it possible then to search the reason for the cognitive abilities in genetic differences?

Sociobiology parts from the assumption that cognition forms are found in the genome (more recently, in the brain). It assumes that cognition forms are already given in the genetic material, and while stored there only wait for an opportunity to manifest. However, the construction of the cognition forms happen on a stage different from the biochemical evolution. 
Scientific review of what happens in evolution allows us to confirm that sociocultural life forms, including cognition, do not take shape in the biological sphere itself, the genome, or the brain. The biological sphere does not know of mental abilities, it only provides the conditions to build them. A "naturalization of the mind" on the understanding of human forms of existence as links to a species evolution is only admissible in the sense that cognitive, linguistic, normative, and esthetic competences are constructed over natural capacities without being stored in them. If we consider the defining role of learning in the acquisition of cognitive competences, belonging to a race lacks explanatory validity when trying to find the reasons that truly allow to understand the differences between individuals in the field of cognition.

\subsection{The detachment of the "ethnicity" variable from the historical and social context}

A second argument in sociobiological studies to be challenged is that the "European ancestry" variable appears detached from its historical and social context; as a consequence, statistical relationships formulated with it do not contribute to consider the true problem posed by the fact that a white minority, those with a European ancestry, in some LatinAmerican countries, show better cognitive abilities and significantly higher income rates than the rest.

If we want to comprehend the relationships between these variables, it is necessary to resort to history to understand what this relationship truly means and contemplate the changes introduced by the democratization in the composition of power in democratic Latin-American societies and which have resulted insufficient to put an end to social inequalities. This is not the place to explain in detail what the links with European ancestors mean sociologically, because this would require a broad and deep reflection, but the situation with the minority of "European ancestors" can at least be mentioned and referred to what is truly significant in current sociological studies: its status in the composition of power.

In Latin America, the European arrival at the beginning of the sixteenth century occurred through a cruel war of conquest. The Spaniards destroyed the old indigenous world and imposed a regime of domination, in which they occupied the positions of civil, ecclesiastical, and military power. The indigenous people were not only plundered but were also subjected and enslaved. After 300 years, the Latin-American criollos started to drive the Spaniards out through the independence war, but this didn't mean a profound change in the conditions of the poor peasants and indigenous people. Independence made way for the development of the middle class and brought a certain improvement in the situation of the mestizos. In Mexico, it wasn't until after the 1910 Revolution that the old rural regime, based on the concentration of land in large private states, disappeared to finally make way in the 1917 Constitution for some of the demands of peasants and workers.

Despite industrial progress, the expansion of the middle class, the considerable increase in miscegenation, and even the democratic advances in Latin-American countries, regional elites have maintained certain ethnic purity since colonial times. However, traits such as skin color and race purity are unimportant in sociological analysis; what truly matters is the permanence of the same elite at the top of the composition of power and the mechanisms that have kept them in power. 
The statistical analysis of European ancestry in a network of variables is irrelevant considering the dramatic fact that, despite the arrival of democracy, those who have European ancestry continue to hold privileged positions in the composition of power, and indigenous people ( $10 \%$ of the Mexican population) keep occupying the population segments in extreme poverty.

\section{Conclusions}

The need to rethink the relationship between empirical research that uses quantitative methods and the articulation of explanations and theories results from three circumstances:

1. The valuable material provided by the comparative-descriptive analysis is insufficient to formulate an explanation of social phenomena.

2. There is a growing theoretical deficit in sociological research due to the impressive amount of first-order observations.

3. Globalization represents a challenge for empirical research, but also for its explanation and theorization.

The aim of this chapter is to state the criteria that sociological reflection must fulfill to articulate an explanation and a theory.

The first one comes from the fundamental change in the history of thought at the beginnings of modern thought, which replaces a logic that resorts to an ultimate absolute origin as explanation for a relational-procedural logic. However, remains of the old logic survive today in numerous explanations, approaches, and theories.

In the modern sense, explaining means to resort to the conditions a phenomenon arises from, in other words, to cognitively recover its intrinsic causality. However, a method that resorts to history is not enough. It requires a second-order observation that analyzes the first-order empirical observations and associates them to other knowledge. Statistical data from empirical research must be subject of a professional sociological observation that correlates it with the knowledge that has been recognized as objective and valid by the scientific community.

The reflections made by a second-order observation of the statistical material from sociobiology, especially those studies that statistically link "European ancestry" with income and cognitive levels, show that in quantitative methodology, variables that in social reality are immersed in a network of historical, social, and political relationships are taken out of context to form part of a two-dimensional statistical model. Without a reflection that contributes to give meaning to the data, the mere enunciation of correlations does not offer possibilities to explain any of the phenomena it deals with.

In the case of the existing relationships between race and cognitive abilities analyzed by the sociobiology, they follow the already historically overcome early logic. This logic parts from what is before it and refers to an origin in which is already contained what is to result from it. 
In this sense, whether in the race or genes, what is to emerge from them is already contained in them. In this reasoning, what truly determines cognitive abilities, the learning development, is left out.

\section{Author details}

Laura Ibarra García

Address all correspondence to: 95nubi@megared.net.mx

University of Guadalajara, Mexico

\section{References}

[1] Eder K. Die EU als entstehender Kommunikationsraum. Zum Theoriedefizit der soziologischen Europaforschung und ein Vorschlag dieses zu verringern. In: Eigmüller M, Mau S, editors. Gesellschaftstheorie und Europapolitik. Sozialwissenschaftliche Ansätze zur Europaforschung. Neue Bibliothek der Sozialwissenschaften. Wiesbaden: Springer VS Verlag für Sozialwissenschaften; 2010. pp. 80-108

[2] Piaget J. Psicología de la inteligencia. Buenos Aires: Editorial Psique; 1972

[3] Bach M. Die Konstitution von Räumen und Grenzbildung in Europa. Von verhandlungsresistenten zu verhandlunsabhängigen Grenzen. In: Eigmüller M, Mau S, editors. Gesellschaftstheorie und Europapolitik. Sozialwissenschaftliche Ansätze zur Europaforschung. Neue Bibliothek der Sozialwissenschaften. Wiesbaden: Springer VS Verlag für Sozialwissenschaften; 2010. pp. 153-178

[4] Vobruba G. Geseellschaftstheoretische Grundlagen der Europasoziologie. Die soziologische Beobachtung der Gesellscahft under Europäischen Integration. In: Eigmüller M, Mau S, editors. Gesellschaftstheorie und Europapolitik. Sozialwissenschaftliche Ansätze zur Europaforschung. Neue Bibliothek der Sozialwissenschafte. Wiesbaden: Springer VS Verlag für Sozialwissenschaften; 2010. pp. 431-470

[5] Bach M. Die Europäisierung der nationalen Gesellschaft Problemstellungen und Perspektiven einer Soziologie der europäischen Integration. In: Bach M, editor. Die Europäisierung nationaler Gesellschaften. Sonderheft der Kölner Zeitschrift für Soziologie und Sozialpsychologie. Vol. 40. 2000. pp. 11-38

[6] Wittgenstein L. Tractatus lógico-philosophicus. Logisch-philosophische Abhandlung. Frankfurt a. M: Suhrkamp; 1971/1918/1921

[7] Dux G. Historisch-genetische Theorie der Kultur. Instabile Welten. Zur prozesualen Logik im kulturellen Wandel. Weilerswist: Velbrück; 2000 
[8] Durkheim E. Las formas elementales de la vida religiosa. España: Ediciones Akal; 1982

[9] Durkheim E. Sociología y Filosofía. Madrid: Miño y Avila Editores; 2000

[10] Dux G. Historisch-genetische Theorie der Kultur. Instabile Welten. Zur prozesualen Logik im kulturellen Wandel. Weilerswist: Velbrück; 2002

[11] Simmel G. Soziologie Untersuchungen über die Formen der Vergesellschaftung. Frank furt a. M: Suhrkamp; 1908/1992

[12] Dux G. Das Subjekt in der Grenze der gesellschaft. In: Nikos Psarros P, StekelerWeithofer GV, editors. Die Entwicklung sozialer Wirklichkeit. Auseinandersetzungen mit der historisch-genetischen Theorie der Gesellschaft. Weilerswist: Velbrück; 2003

[13] Piaget J. Theorien und Methoden der modernen Erziehung. Wien: Verlag Fritz Molden; 1972/1964

[14] Marx K, Engels F. Die deutsche Ideologie. MEW. Vol.3. Berlin: Dietz Verlag; 1969. pp. 9-530

[15] Luhmann N. Die Wissenschaft der Gesellschaft. Frankfurt a. M: Suhrkamp; 1991

[16] Balog A. Der Begrif Gesellschaft. Österreichische Zeitschrift für Soziologie. 1999;24(2):66-93

[17] Durkheim E. La división del trabajo social. Madrid: Akal Ediciones; 1995

[18] Fuerst J, Kirkegaard E. The Genealogy of Differences in the Americas. Mankind Quarterly. 2016;56(3):256-374/252-253

[19] Piffer D. A rewiew of intelligence GWAS hits: Their relationship to country IQ and the issue of spatial autocorrelation. Intelligence. 2015;53:43-50. Available from: https://www. sciencedirect.com/science/article/pii/S0160289615001087

[20] Fedderke J, Klitgaard R, Mac Murray J, Napolini V. Diagnosing deep roots of development: Genetic, desease and environmental factors. Economic Research Southern Africa. 2014. Available from: https:/econrsa.org/system/files/publications/working_papers/ working_paper_465.pdf

[21] Rindermann H. Evolution vs. Culture as background factors for international intelligence differences. Presented at the London Conference of Intelligence. 2015. Retrived from: https://mail.google.com/mail/u/0/\#inbox/14eee641d9da3248?compose=14ef3e99e6 5 c886e\&orojector $=1$

[22] Fuerst J, Kirkegaard E. The genealogy of differences in the Americas. Mankind Quarterly. 2016;56(3):256-374-252-253 